Viscoelastic and chemical properties of dentine after different exposure times to sodium hypochlorite, Ethylenediaminetetraacetic acid and calcium hydroxide

\begin{tabular}{|r|l|}
\hline Journal: & Australian Endodontic Journal \\
\hline Manuscript ID & AEJ-2019-035.R1 \\
\hline Manuscript Type: & Original Research \\
\hline Keywords : & $\begin{array}{l}\text { Sodium hypochlorite, EDTA, calcium hydroxide, dentine, storage } \\
\text { modulus, tan delta, viscoelastic, FTIR }\end{array}$ \\
\hline
\end{tabular}




\title{
Viscoelastic and chemical properties of dentine after different exposure times to sodium hypochlorite, Ethylenediaminetetraacetic acid and calcium hydroxide
}

\begin{abstract}
This study aims to evaluate the viscoelastic and chemical properties of dentine after different durations of exposure to $5.25 \% \mathrm{NaOCl}, 17 \%$ EDTA and $\mathrm{Ca}(\mathrm{OH})_{2}$ solutions, and $\mathrm{NaOCl}$ in alternating combination with EDTA. Standard dentine bars were randomly assigned to: (1) formal-saline control-1; (2) NaOCl; (3) EDTA; (4) NaOCI/EDTA; (5) formal-saline control-2; (6) $\mathrm{Ca}(\mathrm{OH})_{2} \mathrm{pH}$ 12.6; (7) $\mathrm{Ca}(\mathrm{OH})_{2} \mathrm{pH}$ 9.8. Groups 1-4 underwent 10-min cycles of soaking and Dynamic Mechanical Analysis up to 120 min. Groups 5-7 underwent similar tests at days 7, $14,28,84$. FTIR spectra of dentine discs exposed to the same regimens assessed surface chemistry. $\mathrm{NaOCl}$, or $\mathrm{Ca}(\mathrm{OH})_{2}(\mathrm{pH} 12.6)$ solutions reduced the organic $(\mathrm{N}-\mathrm{H}[1], \mathrm{N}-\mathrm{H}[3], \mathrm{C}=0)$ peak components of dentine. This study demonstrated that accumulative damage of dentine could be facilitated by alternated exposure to $\mathrm{NaOCl}$ and EDTA. Exposure of dentine to $\mathrm{Ca}(\mathrm{OH})_{2}(\mathrm{pH} 12.6)$ for 7 days reduced viscous behaviour, inferring increased potential for fatigue failure.
\end{abstract}

Key words: calcium hydroxide, dentine, EDTA, sodium hypochlorite, viscoelastic 


\section{Introduction}

Mechanically, teeth are non-repairing, complex hard tissues, designed to sustain masticatory cyclic loading over elongated life-spans, although they may succumb abruptly to traumatic impact injuries (1). The reputedly higher fracture susceptibility of root-treated teeth may be due to lost tooth structure, altered proprioception or mechanical behaviour of dentine. The latter has been attributed to loss of pulp vitality and exposure of roots to various chemicals (2). Repeated 30-minute irrigation steps with $5.25 \% \mathrm{NaOCl}$ in teeth increased cervical tooth surface strain that plateaued after two steps (3), whereas, alternate irrigation with $5 \% \mathrm{NaOCl} / 17 \%$ EDTA in 30-minute cycles eliminated the plateau (4), allowing continued increase. The altered mechanical behaviour is likely due to depletion of its organic component by $\mathrm{NaOCl}(5)$ and the mineral component by EDTA (6). The effect of subsequent calcium hydroxide dressing for different durations on fracture strength has been confirmed in immature sheep (7) and human (8) incisors. Tests on dentine bars immersed in solutions of $\mathrm{Ca}(\mathrm{OH})_{2}$, found the elastic modulus to be unaltered but flexural strength to be significantly decreased $(9,10)$.

Whole tooth deformation is complex and explained by the relative deformation of bone, periodontal ligament and tooth structures. The strain behaviour of "whole teeth" is complex (11) and not fully explained by quasi-static properties (flexural strength, elastic modulus) of small dentine samples, which are significantly affected by soaking in $\mathrm{NaOCl}$, EDTA and $\mathrm{Ca}(\mathrm{OH})_{2}(3,9)$. Proportional limit, ultimate tensile and micro-punch shear strength of dentine have also been investigated but much still remains to be understood $(12,13)$. The timedependent mechanical behaviour of dentine samples at low cyclic loads may offer better explanation of the behaviour of whole teeth loaded cyclically within their elastic limit (4). However, the effect of root canal irrigants and dressings on the viscoelastic properties of dentine has not been fully tested. Also, the effect of prolonged exposure of dentine to irrigants requires further exploration because it is common for clinicians to flood the pulp 
chamber and root canals with $\mathrm{NaOCl}$ during the entire period of chemo-mechanical preparation (14).

Given the likely importance of viscoelastic properties of teeth on their survival, the aim of this study was to evaluate the time-dependent effect of $\mathrm{NaOCl}(5.25 \%)$ and EDTA $(17 \%)$, independently, or in combination, as well as the effect of $\mathrm{Ca}(\mathrm{OH})_{2}(\mathrm{pH} 12.6$ or 9.8) on the viscoelastic behaviour of dentine using DMA; and explain the changes using FTIR. The null hypotheses for the study were that there was no significant effect of the exposure time of $\mathrm{NaOCl}(5.25 \%)$, EDTA $(17 \%)$ or $\mathrm{Ca}(\mathrm{OH})_{2}(\mathrm{pH} 12.6$ or 9.8$)$ solution on the storage modulus $\left(E^{\prime}\right)$ and tangent delta $(\tan \delta)$ of dentine, with significance set at the $5 \%$ level.

\section{Materials and Methods}

\section{Preparation of dentine specimens}

Human extracted teeth for this study (Study ID: 1301) were supplied by the UCL Eastman Biobank having received favourable opinion from Yorkshire \& The Humber - Leeds East Research Ethics Committee (REC reference: 17/YH/0100). Disease-free, recently extracted, intact wisdom teeththird molars were donated with informed consent by treated patients (age 18 - 34 years) in the Oral Surgery Department (Eastman Dental Hospital) and stored in 4\% formal-saline (BDH Laboratory Supplies, Poole, UK) for no longer than four weeks prior to experimentation. Adherent hard and soft tissue was removed and the teeth decoronated at the cemento-enamel junction. Longitudinal plano-parallel bars were cut from the long axis of the roots, parallel to the bucco-lingual surfaces, using a diamond-coated saw under constant water coolant (Model 60, South Bay Technology inc., Basingstoke, UK). The plane of longitudinal section was at right-angles to the tubule direction.

One hundred and five dentine bars (105 teeth) of standard dimensions (12 $\mathrm{mm} \times 0.8 \mathrm{~mm} \times$ $2 \mathrm{~mm}$ ) were produced; each measured for any variation with a micrometer (Mitutoyo, Kawasaki, Japan) and randomly assigned to one of seven groups for DMA testing (Table 1). 
In addition, 21 square dentine discs $(\underline{4 \mathrm{~mm}} \times \underline{4 \mathrm{~mm} \times 1 \mathrm{~mm}) \text { were prepared from the -crowns }}$ of 21 teeth and randomly subjected to the designated treatments for FTIR evaluation.

\section{Preparation of test solutions}

Sodium hypochlorite (12.75\% - BDH Laboratory Supplies, Poole, UK) was diluted with distilled water and iodometrically titrated to obtain the available chlorine concentration of $5.25 \%$, stored in opaque polyethylene containers and used within $48 \mathrm{~h}$. EDTA (17\%) solution was obtained by dissolving EDTA salt into distilled water with sodium hydroxide salt on a slow magnetic stirrer to $\mathrm{pH}$ 7.8. A saturated solution of calcium hydroxide was prepared by dissolving $40 \mathrm{~g}$ of $\mathrm{Ca}(\mathrm{OH})_{2}$ (BDH Laboratory Supplies, Poole, UK) overnight in $1 \mathrm{~L}$ of distilled water and filtered under vacuum (Whatman, Maidstone, UK). The harvested supernatant of $\mathrm{pH} 12.6$ was diluted to give a second solution of $\mathrm{pH} 9.8$.

\section{Treatment of the dentine bars and discs}

The 60 dentine bars ( $n=15$ per group) and 12 square discs $(n=3$ per group) from groups 1-4 were immersed in their respective test solutions $(25 \mathrm{~mL})$ (Table 1) for 10 minutes in each cycle of soaking and loading for up to 120 minutes. The tests for groups 1-4 were conducted at baseline and repeated 12 times for each sample. The test solutions were freshly changed after each 10-minute soak-period. The group 4 dentine bars were initially soaked in $5 \%$ $\mathrm{NaOCl}$ for 10 minutes, rinsed in distilled water for 10 minutes, and tested by Dynamic Mechanical Analysis (DMA)-tested; the bars were then soaked in 17\% EDTA for 10 minutes, rinsed in distilled water, and DMA-tested again. These two cycles were conducted 6 times. Each bar was marked for orientation to reproducibly return them to the DMA supports in retests.

The 45 bars $(n=15$ per group) and 9 square discs $(n=3$ per group) from groups $5-7$ were individually immersed in the respective test solutions $(25 \mathrm{~mL})$ for 84 days (Table 1$)$. They were DMA-tested at days $0,7,14,28$ and 84 . Each test was preceded by rinsing in $25 \mathrm{~mL}$ distilled water for 10 minutes, blotting on absorbent tissue and air-drying for 10 minutes to 
achieve constant weight. The pre-DMA-test weight of each "air-dried" dentine bar was established using an electronic balance (BDH, Poole, UK), and repeated after the DMA-test.

\section{Dynamic Mechanical Analysis (DMA) conditions}

Each dentine bar was evaluated using flexural testing in a Perkin-Elmer DMA-7, operated with the Pyris software (Perkin-Elmer Corp USA). A 3-point bend testing accessory was used with a $10 \mathrm{~mm}$ span length yielding an average aspect ratio of approximately 13 with a tolerance of +4 or -2 (American Society for Testing and Materials D5023-95a). The loading was parallel to the dentinal tubules. Testing was carried out where the static stress $(240-360$ $\mathrm{mN}$ ) was maintained at a ratio of 1.2 relative to the dynamic stress $(200-300 \mathrm{mN})$, which was applied at a frequency of $1 \mathrm{~Hz}$. A dynamic strain control was maintained at $0.02 \%$. Testing was performed at room temperature for 1 minute and data recorded at $30 \mathrm{~s}$. DMA data were presented as storage modulus $\left(E^{\prime}\right)$ and tangent delta $(\tan \delta)$ versus soaking time.

\section{Fourier Transform Infra-red Spectrometry (FTIR) tests}

Infra-red spectroscopy was performed on treated discs to evaluate compositional change (Perkin Elmer series 2000 FTIR spectrometer; Perkin-Elmer Corp, Waltham, Massachusetts, USA). The absorbance range was set between $500 \mathrm{~cm}^{-1}$ and $4000 \mathrm{~cm}^{-1}$; the resolution was set at 8 ; and the number of scans was 4 . The average spectrum of each set of four repeated scans, and absorbance for each averaged spectrum at specific wavenumbers were obtained using Spectrum ${ }^{\circledR}$ software (Perkin Elmer series 2000). FTIR peaks were assigned for the main components of dentine and compared with existing data $(15,16)$. The collagen and phosphate peak heights at $1640 \mathrm{~cm}^{-1}$ and $1000 \mathrm{~cm}^{-1}$ were obtained by subtracting background absorbance at $1730 \mathrm{~cm}^{-1}$ and $1180 \mathrm{~cm}^{-1}$, respectively.

\section{Statistical analysis}

$E^{\prime}$ and Tan $\delta$ values were calculated using Pyris software; each dentine bar had 13 (groups 1-4) or 5 (groups 5-7) measurements. Kolmogorov-Smirnov and Shapiro-Wilk tests for Normality revealed the data fulfilled the assumption of normal distribution. Mean and 
standard deviation values for $E^{\prime}$ and $\tan \delta$ were calculated for each group. Repeated Measures ANOVA with Bonferroni pairwise comparisons were performed to investigate the effect of exposure time on $E^{\prime}$ and tan $\delta$, (STATA 12; STATA Corporation: College Station, TX, USA), at a significance level of $5 \%$.

\section{Results}

\section{Groups 1-4 (exposure to $5.25 \% \mathrm{NaOCl}$ and/or $17 \%$ EDTA solutions)}

The mean $E^{\prime}$ values plotted against time for each group are shown in Figure 1. Immersion in 17\% EDTA (Group 3) resulted in a small (Range $\sim 10-13 \mathrm{GN} / \mathrm{m}^{2}$ ) but statistically significant decrease in $E^{\prime}$ with time $(P=0.0008)$. Significant decrease in $E^{\prime}$ values (elastic properties) from the baseline was detected after immersion for 60 minutes $(P<0.0001)$ with no further significant change ${ }_{2}$ thereafter. This time-dependent decrease was more marked (Range $10-14 \mathrm{GN} / \mathrm{m}^{2}$ ) and statistically significant when samples were immersed alternately in $5.25 \%$ $\mathrm{NaOCl}$ and $17 \%$ EDTA (Group 4) $(P=0.002)$; the significant change was evident after the $4^{\text {th }}$ cycle of immersion ( 40 minutes in $\mathrm{NaOCl}$ plus 40 minutes in EDTA) $(P<0.0001)$ with no significant change, thereafter.

The mean $\tan \delta$ values plotted against time for each group are also shown in Figure 1. Immersion in $5.25 \% \mathrm{NaOCl}$ (Groups 2) significantly increased tan $\delta$ (viscous behaviour) $(P$ $=0.004)$; the change was noted after the first 10 -minute of immersion with no further increase thereafter. Immersion in 17\% EDTA (Group 3) $(P=0.002)$ resulted in a more consistent increase in tan $\delta$ over time but significant change was only detected after $30-$ minute exposure, with no significant increase thereafter. A significant increase in tan $\delta$ was also observed when dentine bars had been immersed alternately in $5.25 \% \mathrm{NaOCl}$ and $17 \%$ EDTA (Group 4) $(P<0.0001)$. The increase was significant after 30 -minute exposure and gradually continued upto to 70 minutes when a significant $(P=0.02)$ decrease was noted at 80 minutes with no obvious change, thereafter. 
Average FTIR spectra (normalised by the hydroxyapatite $\left[\mathrm{HA}\right.$ ] peak at $1000 \mathrm{~cm}^{-1}$ ) of unreacted samples and those reacted with $5.25 \% \mathrm{NaOCl}$ are shown in Figure 3. The effect of exposure of dentine to $17 \%$ EDTA is shown in the spectra normalised by $\mathrm{N}-\mathrm{H}(3)$ at 1235 $\mathrm{cm}^{-1}$ (Figure 4). Spectra of dentine discs reacted alternately to $5.25 \% \mathrm{NaOCl}$ and $17 \%$ EDTA revealed considerable reduction of the hydroxyapatite peak (HA) at $1000 \mathrm{~cm}^{-1}$ and an appreciable decrease in the organic components: $\mathrm{N}-\mathrm{H}(1)$ and $\mathrm{N}-\mathrm{H}(2)$ bands, which mirrored the FTIR spectra for samples reacted to $5.25 \% \mathrm{NaOCl}$ alone (Figure 5). The water peak $\left(3200 \mathrm{~cm}^{-1}\right)$ had also increased substantially.

\section{Groups 5-7 (exposure to calcium hydroxide solutions)}

The plotted mean data for each group showed consistent but small changes in individual specimens over the twelve-week period (Figure 2). One dentine bar in Group 7 fractured on day 0 , reducing the sample size to 14 . There was significant decrease in $E^{\prime}$ (elastic properties) of dentine bars in group 5 (formal-saline control-2) $(P=0.0002)$ and Group $7(\mathrm{pH}$ 9.8) $(P=0.02)$ after 84 days exposure. There was also a small but statistically significant reduction in tan $\delta$ (viscous behaviour) of the dentine bars over the duration of exposure to pH 12.6 solution (group 6$)(P<0.0001)$; the significant change was noted after 7 days $(P=$ 0.001).

FTIR spectra (normalised at $1000 \mathrm{~cm}^{-1}$ ) showed that the " $\mathrm{C}=\mathrm{O}$ " and " $\mathrm{N}-\mathrm{H}$ " peaks at 1640 $\mathrm{cm}^{-1}$ and $1540 \mathrm{~cm}^{-1}$, respectively, in the organic part of the spectrum, progressively diminished with reaction time with $\mathrm{Ca}(\mathrm{OH})_{2}$, regardless of $\mathrm{pH}$ (Figure 6).

\section{Discussion}

The null hypotheses were rejected as significant changes in the viscoelastic properties of dentine were found upon controlled soaking in $\mathrm{NaOCl}$, EDTA and $\mathrm{Ca}(\mathrm{OH})_{2}$ using Dynamic Mechanical Analysis (DMA). DMA is used to characterises the viscoelastic properties of materials, employing loads within the elastic limit ${ }_{2}$, without permanent sample deformation. It DMA-measures the amplitudes of stress and strain, as well as the phase angle between 
them, enabling resolution of modulus into in-phase (storage modulus; $E^{\prime}$ representing elastic behaviour) and out-of-phase (loss modulus; $E^{\prime \prime}$ describing viscous behaviour) components (12). The relative amount of energy lost to that stored ${ }_{2}$ indicates damping ( $\tan \delta=$ loss modulus $E^{\prime \prime}$ / storage modulus $E^{\prime}$ ).

The proportions of mineral, organic and water (17) dictate the mechanical behaviour of mineralised tissues. The mineral (hydroxyapatite) provides the strength and elasticity, collagen the toughness, and hydrated (plasticised) collagen, the viscous element. Dentine is a composite-fibre structure, peritubular dentine acting as a hypermineralised "fibre" within the intertubular matrix. Tubule direction and the perpendicularly-oriented collagen fibre matrix may contribute to anisotropy (12), which was not evaluated in this study. The close conjunction between mineral and collagen, by virtue of intra-fibrillar and extra-fibrillar collagen mineralisation provides a pre-stressed composite, which upon dehydration consolidates the granular mineral matrix by shrinkage of the interpenetrating collagen, thereby increasing Young's modulus.

The extracted tooth samples were stored in $4 \%$ wt formal-saline for cross-infection control because it does not alter either the FTIR spectra (6) or their mechanical properties (18). Prolonged storage in $4 \%$ formal-saline for upto 84 days (group 5 - control 2) significantly reduced $E^{\prime}$ (elastic behaviour) to a small extent, consistent with loss of mineral (19). A two-hour test span for irrigants was chosen for comparability with previous work $(3,9)$ and clinical relevance (14). The duration of dentine exposure to EDTA during treatment varies between clinicians and the specific rationale for its use. Some advocate EDTA as a routine penultimate root canal irrigation step (20), others as a chelant to aid bacterial load reduction (Bystrom \& Sundqvist 1985) and biofilm degradation $(2,21)$, to remove packed debris from accessory anatomy (22) and open up calcified canal anatomy, where the duration may extend to $2 \mathrm{~h}$ (14). The experimentation partitioned the two-hour test span at 10-minunte intervals for a more precise time-dependent assessment of change in viscoelastic behaviour (23). 
Calcium hydroxide dissociates into calcium and hydroxyl ions in an aqueous solution with a low solubility product, meaning that it is only partially solution, which is important to effect a lasting effect as depletion of the hydroxyl ion drives the equation equilibrium towards more dissolution, thereby maintaining the ionic concentration. The tissue dissolution and antibacterial actions of $\mathrm{Ca}(\mathrm{OH})_{2}$ are attributed to the effect of the hydroxyl ion. It was considered important to control this factor so that the concentration and $\mathrm{pH}$ were maintained. Use of a commercial product would entail the inclusion of other additives that may interfere with this control, hence a saturated solution calcium hydroxide was used.

The test specimens were washed and "air dried" for 10 minutes before testing because it was not possible to test soaking-wet samples. Dehydration affects dentine properties but is dependent on the level of dehydration. The "drying" protocol was tested in pilot experiments at 10-minute intervals over a 2-hour period; measurable change in elasticity was only detected after sixteen minutes of dehydration. The extent of drying in this study therefore had a negligible impact on the results.

In the present study, a constant dynamic strain control of $0.02 \%$ at $37^{\circ} \mathrm{C}$ was not achievable; all tests were therefore run at room temperature. The approach would mitigate dentine dehydration that could occur at higher temperatures and should not alter the final effect but only the rate of reaction. The loading frequency of $1 \mathrm{~Hz}$ was consistent with masticatory frequency $(1-2 \mathrm{~Hz})(1)$; this combined with the 1-minute test period decreased the potential of unwanted strain in the test samples.

The relative lack of effect on $E^{\prime}$ by $5.25 \% \mathrm{NaOCl}$ seems in marked contrast to the changes reported for quasi-static properties of dentine bars, where Young's modulus and flexural strength were reduced significantly $(3,9)$. The data are consistent with the limited tooth surface strain increase (3) evident when irrigating whole teeth. The elastic properties remained unaltered, presumably due to the relative integrity of the mineral phase through its volume (6). It is likely that the minimal but early increase in tan $\delta$ was due to surface collagen degradation limited by the hydroxyapatite (6). 
The dentine bars in the EDTA group exhibited appreciable and significant increases in tan $\delta$, coupled with reduction in $E^{\prime}$. EDTA removes the mineral component (Figure 4), reducing elastic properties. The limited changes in the first 30-minute of exposure may be due to progressive removal of any smear layer (also penetrating dentinal tubules) and subsequently limited by the remaining intact collagen (6). The smear-free tubules and loss of hydroxyapatite from the peritubular and intertubular dentine may allow greater hydration of exposed collagen, explaining the increase in tan $\delta$. However, any further continuing effect may have been limited by re-deposition of mineral or limited penetration along the dentinal tubules.

The dentine bars exposed alternately to $5.25 \% \mathrm{NaOCl}$ and $17 \%$ EDTA, exhibited significant increases in $\tan \delta$ (after 30 minutes) and marked decrease in $E^{\prime}$ (after 80 minutes), consistent with the above observations. The altered mechanical behaviour is also consistent with the increase in tooth surface strain following the same irrigation regimen (4). The significant increase in viscous deformation of dentine, during the first 70 minutes of alternate exposure infers deeper chemical effects on both mineral and collagen phases by the respective agents (6). The increased viscous behaviour infers increased capacity for energy dissipation under stress, coupled with reduced risk of brittle fracture within the elastic limit; however, the simultaneous reduction in modulus would be consistent with reduced dentine fracture toughness after alternate exposure to $\mathrm{NaOCl}$ and EDTA.

The discontinuity in data represented by the abrupt change in tan $\delta$ and $E^{\prime}$ (although less obvious in the latter) between 70 and 80 minute of $\mathrm{NaOCl} /$ EDTA treatment was consistent in 13 of 15 samples. This discontinuity was also evident in groups 1, 2, 3, suggesting cumulative mechanical fatigue, bearing in mind the parallel tubule orientation to loading direction. It is speculated that creep in dentine matrices (24) may slowly alter local stress concentrations at the points of contact between the sample and supports on the test platform, as well as the loading probe. The heightened effect in group 4, may reflect greater instability at the points of contact. FTIR revealed substantial reduction in the $\mathrm{HA}$ and $\mathrm{N}-\mathrm{H}(2)$ peaks from 50- to 80-minute of exposure and explain the mechanical findings. The effects 
seen in the EDTA/NaOCl group may potentially reflect an increased susceptibility to crack propagation without the protective mechanisms of hydrated collagen (25).

Dentine bars exposed to stock (group 6) or diluted (group 7) calcium hydroxide solutions only exhibited small changes in their $E^{\prime}$ after immersion for 84 days in diluted solution. This seems consistent with the micromechanical model because a saturated calcium solution, albeit at a high $\mathrm{pH}$, may deplete the mineral content (Figure 6) of dentine to a small extent (19). The bars exposed to the stock solution (pH 12.6) (group 6) exhibited reduced viscous behaviour, possibly due to complete denaturation of the exposed collagen (26), which may in turn influence its state of hydration and thus viscoelasticity (27). The calcium hydroxide solutions exhibited constant initial $\mathrm{pH}$, which dropped upon exposure to dentine, explained by depletion of hydroxyl ions through reaction with dentine collagen (28). The findings are consistent with the observation that dentine bars exposed to calcium hydroxide did not exhibit altered Young's modulus $(9,10)$ but reduced flexural strength $(7,8)$. Grigoratos et al. (9) explained the disparate effects by the observation that the restricted surface effect would influence the two properties differently. Further research to explore the location of boundary of such chemical and physical changes is merited.

The present findings emphasise the need for caution in selecting the duration of alternated exposure to $17 \%$ EDTA and $5.25 \% \mathrm{NaOCl}$ solutions $(4,29)$, although greater frequency of alternation between the two solutions clinically may simply neutralise $\mathrm{NaOCl}(30)$ and hence the overall effect on tooth surface strain (23). Neutralisation was avoided in the present study by washing with saline between alternate exposures to each solution, allowing the accumulative effect to manifest.

\section{Conclusions}

The present data signify that $\mathrm{NaOCl}$ and EDTA independently may influence dentine viscoelasticity in different and self-limiting ways over the duration of exposure. However, alternation between EDTA and $\mathrm{NaOCI}$ facilitates accumulative damage. $\mathrm{Ca}(\mathrm{OH})_{2}$ at $\mathrm{pH} 12.6$ 
induced significant reduction in viscous behaviour (tan $\delta$ ) of dentine, inferring increased potential for fatigue failure. 


\section{Figure captions}

Figure 1 The mean and standard deviation values for storage modulus (EI) (GNm-2) and tan delta (tan $\delta$ ) plotted against time for groups 1-4 (Group 1 Formal-saline; Group $2 \mathrm{NaOCl}$; Group 3 EDTA; Group 4 NaOCl/EDTA).

Figure 2 The mean and standard deviation values for Storage Modulus $\left(E^{\prime}\right)\left(\mathrm{GNm}^{-2}\right)$ and Tan delta $\left(\tan \delta\right.$ ) plotted against time for groups 5-7 (Group 5 Saline; Group $6 \mathrm{Ca}[\mathrm{OH}]_{2} \mathrm{pH} 12.6$; Group $\left.7 \mathrm{Ca}[\mathrm{OH}]_{2} \mathrm{pH} 9.8\right)$.

Figure 3 Average FTIR spectra $(n=3)$ of dentine discs reacted with 5.25 wt $\% \mathrm{NaOCl}$ for 0 , $20,50,80$ or 110 minutes.

Figure 4 Average FTIR spectra $(n=3)$ of dentine discs reacted with 17 wt $\%$ EDTA for 0,20 , 50,80 or 110 minutes.

Figure 5 Average FTIR spectra $(n=3)$ of dentine discs reacted with $17 w t \%$ EDTA / 5.25 wt $\%$ $\mathrm{NaOCl}$ for $20,50,80$ or 110 minutes.

Figure 6 Average FTIR spectra of dentine discs reacted with $\mathrm{Ca}(\mathrm{OH})_{2}$ at $\mathrm{pH} 12.7$ (high) or 9.8 (low) for 28 days.

\section{Table caption}

Table 1 Group composition, test conditions and sample size. 


\section{Table 1: Group composition, test conditions and sample size}

\begin{tabular}{|c|c|c|c|c|c|c|c|}
\hline Group & Test Media & $\begin{array}{l}\text { No. of dentine } \\
\text { bars for DMA }\end{array}$ & Soaking cycle & $\begin{array}{l}\text { Washing cycle in } \\
\mathrm{H}_{2} \mathrm{O} \\
\text { (10 mins in } 25 \mathrm{~mL} \text { ) }\end{array}$ & $\begin{array}{l}\text { Test } \\
\text { cycle } \\
(1 \mathrm{~min})\end{array}$ & $\begin{array}{c}\text { Cycle } \\
\text { repeats }\end{array}$ & $\begin{array}{c}\text { Data } \\
\text { points }\end{array}$ \\
\hline $\begin{array}{l}\text { Group } 1 \\
\text { (Control-1) }\end{array}$ & 4\% Formal-saline & 15 & $10 \mathrm{~min}$ in $25 \mathrm{~mL}$ & $\checkmark$ & $\checkmark$ & 12 & 13 \\
\hline Group 2 & $5.25 \% \mathrm{NaOCl}$ & 15 & $10 \mathrm{~min}$ in $25 \mathrm{~mL}$ & $\checkmark$ & $\checkmark$ & 12 & 13 \\
\hline Group 3 & $17 \%$ EDTA & 15 & $10 \mathrm{~min}$ in $25 \mathrm{~mL}$ & $\checkmark$ & $\checkmark$ & 12 & 13 \\
\hline Group 4 & $17 \%$ EDTA / $5.25 \% \mathrm{NaOCl}$ & 15 & $10 \mathrm{~min}$ in $25 \mathrm{~mL}$ & $\checkmark$ & $\checkmark$ & 12 & 13 \\
\hline $\begin{array}{l}\text { Group } 5 \\
\text { (Control-2) }\end{array}$ & $4 \%$ Saline & 15 & $1,2,4,12 \mathrm{wks}$ in $25 \mathrm{~mL}$ & $\checkmark$ & $\checkmark$ & 4 & 5 \\
\hline Group 6 & $\mathrm{Ca}(\mathrm{OH})_{2}$ with high $\mathrm{pH}(12.7)$ & 15 & $1,2,4,12 \mathrm{wks}$ in $25 \mathrm{~mL}$ & $\checkmark$ & $\checkmark$ & 4 & 5 \\
\hline Group 7 & $\mathrm{Ca}(\mathrm{OH})_{2}$ with low $\mathrm{pH}(9.8)$ & 15 & $1,2,4,12 \mathrm{wks}$ in $25 \mathrm{~mL}$ & $\checkmark$ & $\checkmark$ & 4 & 5 \\
\hline Total & & 105 & & & & & \\
\hline
\end{tabular}




\section{References}

1. Zaslansky P, Currey JD, Fleck C. Learning from evolutionary optimisation: what are toughening mechanisms good for in dentine, a nonrepairing bone tissue? Bioinspir Biomim. 2016;11(5):051003.

2. Gulabivala K, Patel B, Evans G, Ng YL. Effects of mechanical and chemical procedures on root canal surfaces. Endodontic Topics. 2005;10(1):103-22.

3. Sim TP, Knowles JC, Ng YL, Shelton J, Gulabivala K. Effect of sodium hypochlorite on mechanical properties of dentine and tooth surface strain. Int Endod J. 2001;34(2):120-32.

4. Rajasingham R, Ng YL, Knowles JC, Gulabivala K. The effect of sodium hypochlorite and ethylenediaminetetraacetic acid irrigation, individually and in alternation, on tooth surface strain. Int Endod J. 2010;43(1):31-40.

5. Driscoll CO, Dowker SE, Anderson P, Wilson RM, Gulabivala K. Effects of sodium hypochlorite solution on root dentine composition. J Mater Sci Mater Med. 2002;13(2):219-23.

6. Ramirez-Bommer C, Gulabivala K, Ng YL, Young A. Estimated depth of apatite and collagen degradation in human dentine by sequential exposure to sodium hypochlorite and EDTA: a quantitative FTIR study. Int Endod J. 2018;51(4):469-78.

7. Andreasen JO, Farik B, Munksgaard EC. Long-term calcium hydroxide as a root canal dressing may increase risk of root fracture. Dent Traumatol. 2002;18(3):134-7.

8. Rosenberg B, Murray PE, Namerow K. The effect of calcium hydroxide root filling on dentin fracture strength. Dental Traumatology. 2007;23(1):26-9.

9. Grigoratos D, Knowles J, Ng YL, Gulabivala K. Effect of exposing dentine to sodium hypochlorite and calcium hydroxide on its flexural strength and elastic modulus. Int Endod J. 2001;34(2):113-9.

10. Marending M, Stark WJ, Brunner TJ, Fischer J, Zehnder M. Comparative assessment of timerelated bioactive glass and calcium hydroxide effects on mechanical properties of human root dentin. Dent Traumatol. 2009;25(1):126-9.

11. Kishen A, Asundi A. Experimental investigation on the role of water in the mechanical behavior of structural dentine. J Biomed Mater Res A. 2005;73(2):192-200.

12. Kinney JH, Marshall SJ, Marshall GW. The mechanical properties of human dentin: a critical review and re-evaluation of the dental literature. Crit Rev Oral Biol Med. 2003;14(1):13-29.

13. Seyedkavoosi S, Zaytsev D, Drach B, Panfilov P, Gutkin MY, Sevostianov I. Fractionexponential representation of the viscoelastic properties of dentin. Int J Eng Sci. 2017;111:52-60.

14. Gu LS, Huang XQ, Griffin B, Bergeron BR, Pashley DH, Niu LN, et al. Primum non nocere The effects of sodium hypochlorite on dentin as used in endodontics. Acta Biomater. 2017;61:14456.

15. Muyonga J, Cole C, Duodu K. Fourier transform infrared (FTIR) spectroscopic study of acid soluble collagen and gelatin from skins and bones of young and adult Nile perch (Lates niloticus). Food Chemistry. 2004;86(3):325-32.

16. Tomson R. The effect of calcium hydroxide, sodium hypochlorite and ethylenediaminetetraacetic acid on the chemical compostion of dentine. London, UK: University College London; 2004.

17. Currey JD. The design of mineralised hard tissues for their mechanical functions. J Exp Biol. 1999;202(Pt 23):3285-94.

18. Jameson MW, Tidmarsh BG, Hood JA. Effect of storage media on subsequent water loss and regain by human and bovine dentine and on mechanical properties of human dentine in vitro. Arch Oral Biol. 1994;39(9):759-67.

19. Habelitz S, Marshall GW, Jr., Balooch M, Marshall SJ. Nanoindentation and storage of teeth. J Biomech. 2002;35(7):995-8.

20. Ng YL, Mann V, Gulabivala K. A prospective study of the factors affecting outcomes of nonsurgical root canal treatment: part 1: periapical health. Int Endod J. 2011;44(7):583-609. 
21. Bystrom A, Sundqvist $\mathrm{G}$. The antibacterial action of sodium hypochlorite and EDTA in 60 cases of endodontic therapy. Int Endod J. 1985;18(1):35-40.

22. Paque $\mathrm{F}, \mathrm{Al}$-Jadaa A, Kfir A. Hard-tissue debris accumulation created by conventional rotary versus self-adjusting file instrumentation in mesial root canal systems of mandibular molars. Int Endod J. 2012;45(5):413-8.

23. Sobhani OE, Gulabivala K, Knowles JC, Ng YL. The effect of irrigation time, root morphology and dentine thickness on tooth surface strain when using $5 \%$ sodium hypochlorite and $17 \%$ EDTA. Int Endod J. 2010;43(3):190-9.

24. Pashley DH, Agee KA, Wataha JC, Rueggeberg F, Ceballos L, Itou K, et al. Viscoelastic properties of demineralized dentin matrix. Dent Mater. 2003;19(8):700-6.

25. Kruzic JJ, Nalla RK, Kinney JH, Ritchie RO. Mechanistic aspects of in vitro fatigue-crack growth in dentin. Biomaterials. 2005;26(10):1195-204.

26. Hasselgren $G$, Olsson B, Cvek M. Effects of calcium hydroxide and sodium hypochlorite on the dissolution of necrotic porcine muscle tissue. J Endod. 1988;14(3):125-7.

27. Gevorkian SG, Allahverdyan AE, Gevorgyan DS, Simonian AL, Hu CK. Stabilization and anomalous hydration of collagen fibril under heating. PLoS One. 2013;8(11):e78526.

28. Haapasalo HK, Siren EK, Waltimo TM, Orstavik D, Haapasalo MP. Inactivation of local root canal medicaments by dentine: an in vitro study. Int Endod J. 2000;33(2):126-31.

29. Calt S, Serper A. Time-dependent effects of EDTA on dentin structures. J Endod. 2002;28(1):17-9.

30. Grande NM, Plotino G, Falanga A, Pomponi M, Somma F. Interaction between EDTA and sodium hypochlorite: a nuclear magnetic resonance analysis. J Endod. 2006;32(5):460-4. 
Figure 1 shows the mean and standard deviation values for storage modulus (EI) $\left(\mathrm{GNm}^{-2}\right)$ and tan delta (tan $\delta$ ) plotted against time for groups 1-4 (Group 1 Formal-saline; Group 2 NaOCl; Group 3 EDTA; Group 4 $\mathrm{NaOCl} / \mathrm{EDTA})$. 

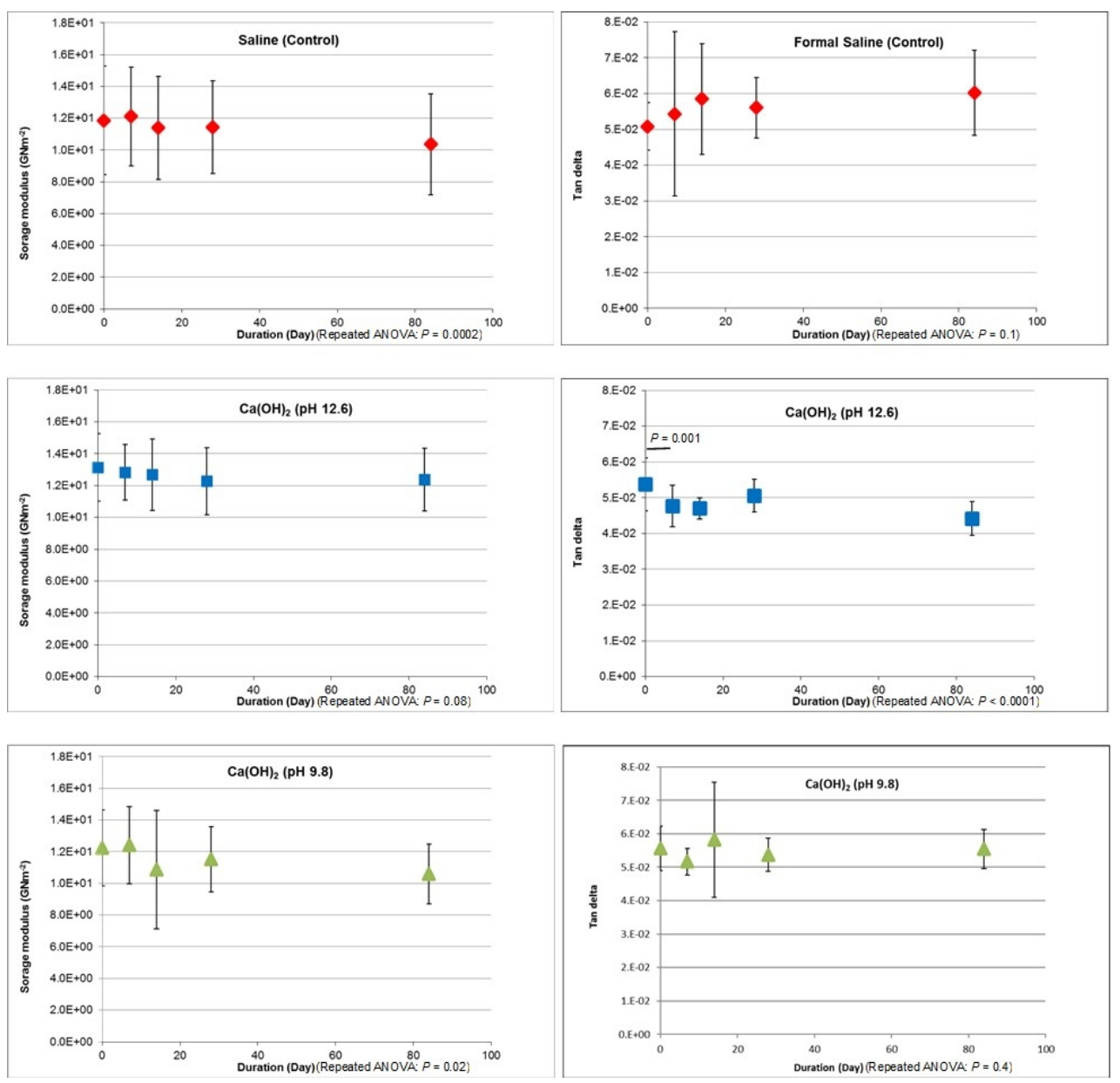

Figure 2 shows the mean and standard deviation values for Storage Modulus (EI) (GNm ${ }^{-2}$ ) and Tan delta (tan $\delta$ ) plotted against time for groups 5-7 (Group 5 Formal-Saline; Group $6 \mathrm{Ca}[\mathrm{OH}]_{2} \mathrm{pH}$ 12.6; Group 7 $\mathrm{Ca}[\mathrm{OH}]_{2} \mathrm{pH}$ 9.8).

$170 \times 160 \mathrm{~mm}(150 \times 150 \mathrm{DPI})$ 
Figure 3 Average FTIR spectra $(n=3)$ of dentine discs reacted with $5.25 \mathrm{wt} \% \mathrm{NaOCl}$ for $0,20,50,80$ or 110 minutes.

$159 \times 96 \mathrm{~mm}(150 \times 150 \mathrm{DPI})$ 


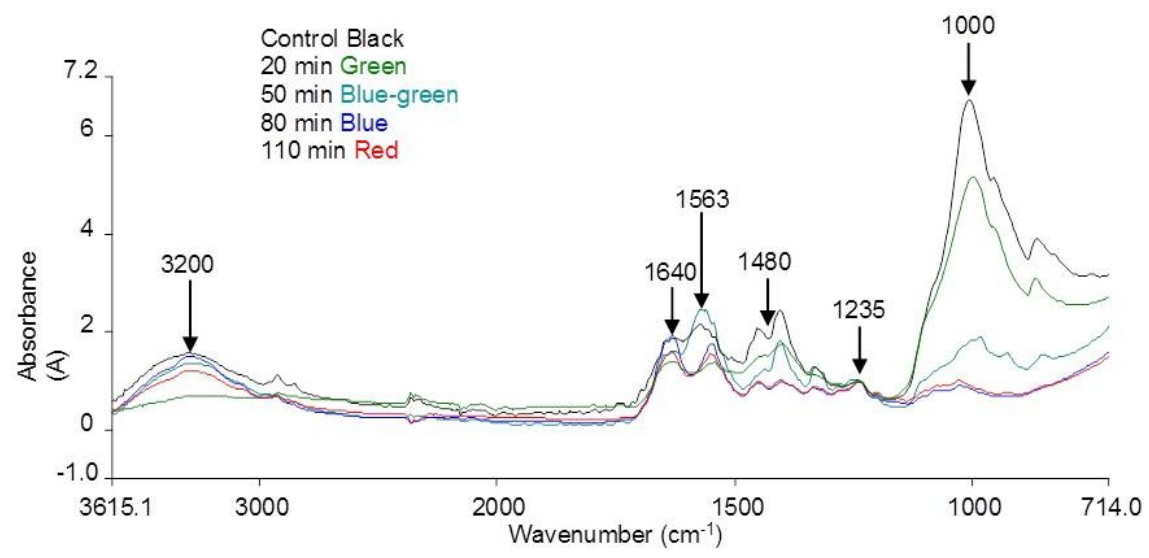

Figure 4 Average FTIR spectra $(n=3)$ of dentine discs reacted with 17 wt\% EDTA for $0,20,50,80$ or 110 minutes.

$170 \times 77 \mathrm{~mm}(150 \times 150 \mathrm{DPI})$ 
Figure 5 Average FTIR spectra $(n=3)$ of dentine discs reacted with $17 \mathrm{wt} \%$ EDTA / $5.25 \mathrm{wt} \% \mathrm{NaOCl}$ for 20, 50,80 or 110 minutes.

$170 \times 100 \mathrm{~mm}(150 \times 150 \mathrm{DPI})$ 


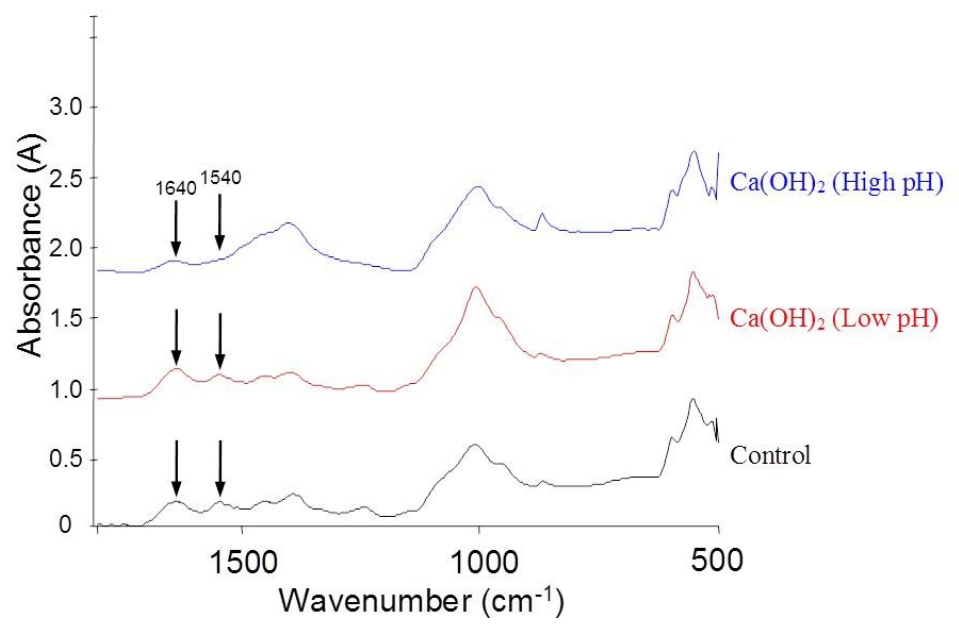

Figure 6 Average FTIR spectra of dentine discs reacted with $\mathrm{Ca}(\mathrm{OH})_{2}$ at $\mathrm{pH} 12.7$ (high) or 9.8 (low) for 28 days.

$207 \times 125 \mathrm{~mm}(150 \times 150$ DPI $)$ 